\title{
PEMANFAATAN CITRA KAMERA INFRAMERAH THERMAL (KIT) UNTUK MENDETEKSI AREA INFLAMASI PADA TUBUH MANUSIA
}

\author{
THE UTILIZATION OF THERMAL IMAGING INFRARED CAMERA \\ TO DETECT INFLAMMATION AREA IN THE HUMAN BODY
}

\author{
Mardon Limena, Giner Maslebu, Ferdy S. Rondonuwu* \\ Fakultas Sains dan Matematika, Universitas Kristen Satya Wacana \\ Submitted:15-10-2018; Revised:03-05-2021; Accepted:23-07-2021
}

\begin{abstract}
Inflammation is an indication of an abnormality in the human body. Cases of inflammation occur accompanied by changes in temperature on the surface of the body. The location and location of the spread of inflammation cannot be seen solely by the human eye in detail. An imaging modality tool that is suitable for use in observing this problem is needed. In this study, the Thermal Infrared Camera (TIC) is used as an imaging modality. Samples in the form of a pair of legs in which one part of inflammation occurs are used as research objects. TIC is an imaging modality tool that can detect temperatures on the surface of an object quickly and is nondestructive. The results of the TIC image are processed using the global thresholding image processing method to distinguish between the inflammatory areas and normal areas more specifically. The results displayed indicate that there are differences in the image between the area of inflammation with the normal area of the patient's feet. The results of image processing data in the form of binary images show between the inflammatory area represented by white and vice versa the normal area represented by black. A comparison between the two conditions of the patient's feet before and after recovery shows the shrinkage of the area. There are two main results obtained in the exploration of this research, which is successful in distinguishing the inflammatory area from the normal area and the progress of recovery from the legs of the affected patient.
\end{abstract}

Keywords: Global Thresholding; Image Processing; Inflamation; TIC.

\begin{abstract}
ABSTRAK
Inflamasi merupakan suatu bentuk indikasi terjadinya suatu kelainan pada tubuh manusia. Kasus inflamasi terjadi disertai dengan perubahan temperatur pada permukaan tubuh. Lokasi beserta letak penyebaran dari inflamasi tidak dapat semata-mata terlihat oleh mata manusia secara detail. Diperlukan suatu alat modalitas pencitraan yang cocok untuk digunakan dalam pengamatan masalah ini. Kamera Inframerah Thermal (KIT) pada penelitian ini,) digunakan sebagai modalitas pencitraan. Sampel berupa sepasang kaki yang salah satu bagiannya terjadi inflamasi digunakan sebagai objek penelitian. KIT merupakan alat modalitas pencitraan yang dapat mendeteksi temperatur pada permukaan suatu objek dengan cepat dan bersifat non destruktif. Hasil citra KIT diolah dengan metode pengolahan citra global thresholding guna membedakan antara area inflamasi dan area normal secara lebih spesifik. Hasil yang ditampilkan menunjukan bahwa adanya perbedaan citra antara area inflamasi dengan area normal pada kaki pasien. Hasil data pengolahan citra yang berbentuk citra biner memperlihatkan antara area inflamasi yang diwakili warna putih dan sebaliknya area normal diwakili warna hitam. Perbandingan
\end{abstract}

\footnotetext{
* Corresponding author: ferdy@staff.uksw.edu

Copyright (2021 THE AUTHOR(S). This article is distributed under a Creative Commons Attribution-Share Alike 4.0 International license. Jurnal Teknosains is published by the Graduate School of Universitas Gadjah Mada
} 
antara kedua kondisi kaki pasien sebelum dan sesudah pemulihan menunukkan adanya penyusutan luas area. Terdapat dua hasil pokok yang diperoleh pada eksplorasi penelitian ini yaitu berhasil membedakan daerah inflamasi dengan daerah normal serta progress pemulihan dari bagian kaki pasien yang mengalami tersebut.

Kata Kunci: Global Thresholding; Inflamasi; KIT; Pengolahan citra.

\section{PENGANTAR}

Pengamatan pada kondisi kesehatan tubuh (medical screening) merupakan suatu tindakan medis yang bertujuan untuk mengecek kondisi kesehatan ataupun mendeteksi suatu penyakit pada tubuh manusia. Salah satu masalah kesehatan yang sering menghampiri tubuh manusia adalah inflamasi. Inflamasi atau peradangan merupakan suatu bentuk respon sistem kekebalan tubuh terhadap suatu masalah yang mengganggu atau bahkan merusak sistem biologis manusia. Kasus inflamasi terjadi disertai dengan perubahan kalor pada permukaan tubuh. Daerah inflamasi pada tubuh menjadi lebih panas dari sekelilingnya dikarenakan darah yang disalurkan oleh tubuh kepermukaan daerah inflamasi lebih banyak daripada yang disalurkan ke daerah normal (Nahm, 2013).

Kamera Inframerah Thermal (KIT) merupakan alat yang menerapkan konsep termografi dalam menghasilkan sebuah citra (Lasanen, 2015). Termografi merupakan metode pencitraan dengan mendeteksi emisi radiasi inframerah yang dipancarkan oleh suatu benda yang memiliki suhu tertentu diatas nilai absolut $0 \mathrm{~K}\left(-273{ }^{\circ} \mathrm{C}\right)$. Seperti yang dijelaskan pada hukum Planck dan Stefan Boltzman mengenai radiasi thermal bahwa sebuah benda tidak perlu sangat panas untuk bisa memancarkan gelombang elektromagnetik. Semua benda memancarkan energi thermal secara kontinu. Pada temperatur kamar sebagian besar radiasi yang dipancarkan terdapat pada region inframerah dari spektrum gelombang elektromagnetik (Cardone \& Merla, 2017). Semakin tinggi temperatur sebuah objek semakin tinggi pula emisi radiasi inframerah yang dipancarkan. (Gurjarpadhye, Parekh, Dubnika, Rajadas, \& Inayathullah, 2015).
Gelombang inframerah memiliki panjang gelombang lebih besar ketimbang cahaya tampak yang berkisar diangka 400-700 nm sehingga tak dapat dilihat langsung oleh manusia. Panjang gelombang inframerah secara keseluruhan berkisar antara 750-1.000.000 nm. Energi thermal berupa gelombang inframerah yang didapatkan kemudian dikonversi menjadi bentuk tampilan citra yang dapat diamati oleh manusia. (Ranosz-Janicka, Lis-Święty, Skrzypek-Salamon, \& Brzezińska-Wcisło, 2019). Termografi memungkinkan kita untuk melihat sesuatu yang tak dapat terlihat oleh mata manusia secara langsung (Lasanen, 2015).

Pengolahan citra diterapkan guna mengungkap lebih dalam informasi yang tersedia dalam sebuah citra thermal. Pada era digital ini output dari citra kamera tentunya dalam bentuk digital, begitu pula dengan KIT yang digunakan dalam penelitian ini. Citra digital adalah representasi dari fungsi intensitas cahaya dalam bentuk diskrit pada bidang dua dimensi (Brody, 2000). Citra tersusun oleh sekumpulan piksel (picture element) yang memiliki koordinat $(\mathrm{x}, \mathrm{y})$ dan amplitudo $f(x, y)$. Pengolahan citra pada penelitian ini menitik beratkan pada bagian segmentasi citra (global thresholding). Segmentasi citra berguna memisahkan suatu citra menjadi beberapa bagian (region) sesuai keperluan.

Secara matematis dapat dituliskan pada persamaan (1) (Brody, 2000):

$$
g(x, y)=\left\{\frac{1, j i k a(x, y)>T}{0, j i k a(x, y) \leq T}\right.
$$

keterangan:

$\mathrm{T}=$ nilai threshold

Segmentasi pada umumnya digunakan untuk membedakan objek citra yang ingin diamati secara detail (region of interest) foreground terhadap background disekitarnya yang tidak diperlukan ataupun tidak ingin diamati. Sederhananya hasil segmentasi citra hanya menjadi dua kelas bagian yaitu foreground dan background (Bushberg, 2012). Eksplorasi hasil pemgolahan citra thermal ini diharapkan dapat menghasilkan data yang berguna untuk proses pengamatan serta pemetaan area inflamasi pada suatu bagian tubuh manusia secara lebih 
detail. Berdasarkan citra biner yang dihasilkan, dapat dinyatakan bahwa area foreground (putih) pada citra mengindikasikan bagian area inflamasi. Fungsi bwarea digunakan untuk mencari perhitungan luasan area foreground (putih) dalam bentuk pixel. Perlu dilakukan sebuah konversi agar dapat menyatakan luasan area tersebut kedalam bentuk real. Bentuk real yang dimaksud adalah luasan dalam satuan $\mathrm{cm}$ bukan pixel lagi. Untuk melakukan konversi dari bentuk pixel ke $\mathrm{cm}$ diperlukan sebuah faktor konversi. Faktor konversi yang diperlukan adalah resolusi spasial pada citra yang dihasilkan oleh KIT. Resolusi spasial merupakan ketelitian sebuah citra untuk menampilkan objek dengan jelas. Sebelum mengetahui suatu resolusi spasial pada citra diperlukan informasi mengenai panjang yang dimiliki sebuah pixel. Seperti yang telah disebutkan pada spesifikasi alat bahwa pada jarak sekitar 1 meter dari objek, KIT menghasilkan citra dengan panjang sisi $1.36 \mathrm{~mm}$ untuk setiap pixel yang dimilikinya. Persamaan umum resolusi spasial dapat dituliskan pada persamaan (2) (Bushberg, 2012; Maslebu, Adi, \& Suryono, 2016):

Resolusi spasial $=\frac{\text { pixel }}{\mathrm{cm}^{2}}$.

Dari informasi yang telah diperoleh, maka diperoleh persamaan (3):

Resolusi spasial $=\frac{1 \mathrm{pixel}}{0.136 \mathrm{~cm} \times 0.136 \mathrm{~cm}}$

Sehingga diperoleh nilai resolusi spasial sebesar 54.07 pixel $/ \mathrm{cm}^{2}$

Perhitungan luasan area sebenarnya pada inflamasi ditunjukan oleh persamaan (4):

Luas area $\left(\mathrm{cm}^{2}\right)=\frac{\text { Luas bw area }(\text { pixel })}{\text { Resolusi spasial }\left(\frac{\text { pixel }}{\mathrm{cm}^{2}}\right)}$.

\section{Metode}

Dalam mencapai tujuan penelitian ini telah diterapkan beberapa tahapan. Perihal tersebut meliputi pengambilan citra, pengolahan citra, dan eksplorasi perhitungan luasan area inflamasi. Detail mengenai diagram alur pengolahan citra pada penelitian ini ditunjukan pada Gambar 1.

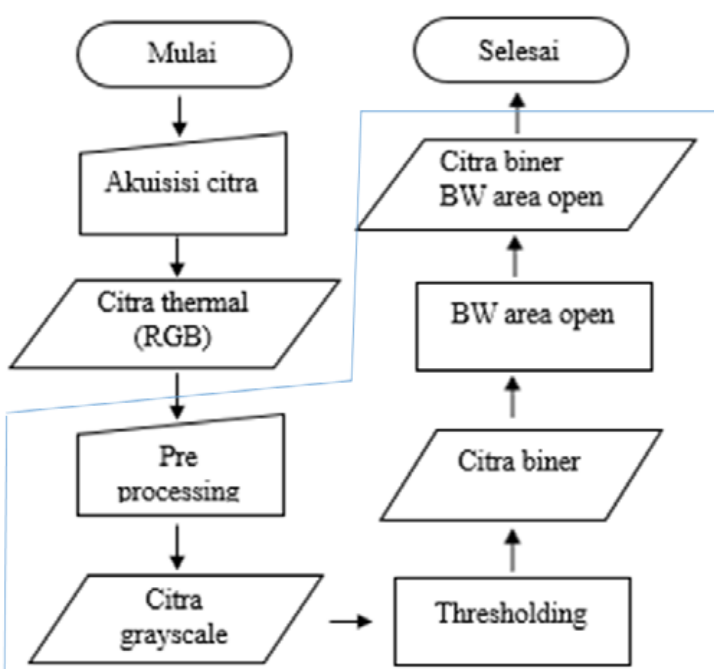

Gambar 1.

Diagram alur pengolahan citra, area yang ditandai dengan garis biru merupakan proses pengolahan citra menggunakan matlab.

\section{Alat dan sampel}

Objek yang dipilih pada penelitian ini berupa sepasang kaki pasien yang salah satu sisinya (kaki kiri) mengalami inflamasi pasca operasi. Bermodalkan kamera inframerah thermal (KIT) FLIR Exx-Series E60 pengambilan data dilakukan dengan pemotretan pada area kedua kaki pasien. Pemotretan dilakukan sebanyak dua kali pertemuan dalam jangka waktu yang berbeda. Pada Gambar 2(a) merupakan pertemuan pertama ketika pasien belum melalui proses terapi/ pemulihan, sedangkan pada Gambar 2(b) merupakan pertemuan kedua setelah pasien melalui proses terapi/ pemulihan dalam rentang waktu kurang lebih 1 bulan.

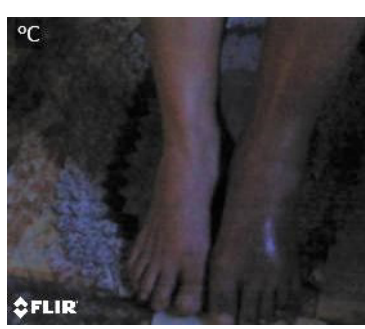

(a)

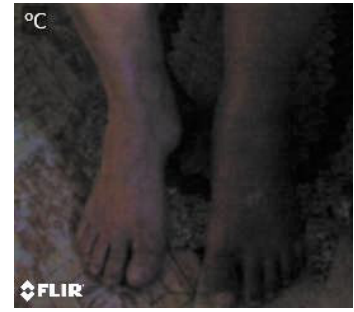

(b)
Gambar 2.

Citra Visible Light Pada Pasien Hasil Pemindaian Objek

(a) sebelum pemulihan; (b) setelah pemulihan 
KIT FLIR Exx-Series E60 ini memiliki spesifikasi diantaranya resolusi pixel thermal $320 \times 240$, resolusi thermal $0.05^{\circ} \mathrm{C}$, spectral range untuk radiasi inframerah yang dapat terdeteksi detektor antara 7.5-13 $\mu \mathrm{m}$, Field of view (FOV) lensa $25^{\circ} \times 19^{\circ}$, Instantaneous field of view (IFOV) / spatial resolution 1.36 rad yang berarti pada jarak pengamatan $1 \mathrm{~m}$ tiap pixel memiliki ukuran sekitar 1,36 mm (Fluke, 2010). Pabrikan kamera ini menyarankan pengamatan area terkecil berukuran $3 \times 3$ area pixel (Anonym, 2016). Artinya pada jarak $1 \mathrm{~m}$ area terkecil pada objek yang disarankan dapat terlihat dengan baik kurang lebih berukuran sekitar $4.08 \times 4.08$ $\mathrm{mm}^{2}$.

\section{Pengambilan citra}

Terdapat beberapa faktor yang perlu diperhatikan dalam tahap pengambilan citra. Faktor yang perlu diperhatikan antara lain ialah benda disekitar lokasi pemotretan sampel, temperatur diruangan pemotretan, dan karakteristik material penyusun dari sampel. Semua hal yang telah disebutkan dapat mempengaruhi temperatur pada sampel yang sedang diamati (Lasanen, 2015). Selain itu, untuk memperoleh data citra yang komprehensif untuk disajikan telah dilakukan beberapa uji pemotretan. Hal tersebut terkait pengaturan kamera dengan opsi yang tepat sesuai dengan sampel yang diamati Beberapa aspek pengaturan meliputi: skala temperatur dibuat secara manual dengan batas atas $36^{\circ} \mathrm{C}$ dan batas bawah $26^{\circ} \mathrm{C}$, pola warna dipilih rainbow color, parameter pengukuran default (emissivity: 0.95 , reflected temperature: $20^{\circ} \mathrm{C}$, distance: $1 \mathrm{~m}$, atmospheric temperature: $20^{\circ} \mathrm{C}$ ).

Pemotretan sampel dilakukan di kamar tempat tidur pasien dengan posisi pasien duduk tegak menghadap kamera. Jarak konsisten dipilih +/- 1 meter (aspek ini mempengaruhi IFOV/spatial resolution citra thermal yang dihasilkan) (Anonym, 2018). Aspek jarak dan sudut pemotretan belum diukur secara presisi disebabkan keterbatasan preparasi pengambilan data. Pemotretan kedua kondisi kaki pada pasien sebelum dan pasca pemulihan dilakukan seidentik mungkin.

\section{HASIL DAN PEMBAHASAN Citra thermal}

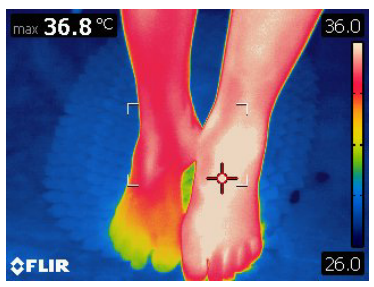

(a)

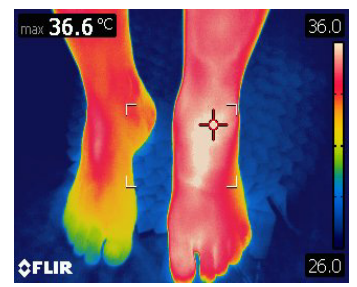

(b)
Gambar 3

Citra Thermal Hasil Pemindaian Objek (a) sebelum pemulihan; (b) setelah pemulihan.

Tabel 1.

Klasifikasi pola warna berdasarkan skala temperatur

\begin{tabular}{ll}
\hline \multicolumn{1}{c}{ Skala temperatur $\left({ }^{\circ} \mathrm{C}\right)$} & \multicolumn{1}{c}{ Pola warna } \\
\hline $26-28.5$ & Hitam - Biru \\
$28.5-31$ & Biru - Hijau, Kuning \\
$31-33.5$ & Kuning - Merah \\
$33.5-36$ & Merah - Putih \\
\hline
\end{tabular}

Gambar 2 merupakan hasil dari akuisisi citra menggunanakan KIT. Skala temperatur yang ditunjukan pada kedua citra thermal mengggunakan palet warna rainbow. Citra pada kedua kondisi diatur dengan skala temperatur yang identik agar menghasilkan perbandingan yang tepat. Kursor pada gambar menunjukan titik nilai temperatur tertinggi (hotspot) pada objek. Sebaran warna yang mewakili nilai temperatur. Hasil menunjukan perbedaan temperatur antara kaki kanan (normal) dan kaki kiri (inflamasi). Citra thermal dari kondisi pasien setelah pemulihan (b) memperlihatkan pengecilan area sebaran warna yang terdapat pada kaki kiri (inflamasi) jika dibandingkan dengan kondisi pasien sebelum pemulihan (a). Tampilan warna ini mendefinisikan titik nilai temperatur menjadi beberapa bagian warna. Mulai dari yang tertinggi putih dilanjutkan merah, kuning hijau, biru, hingga terendah hitam. Kaki kiri yang merupakan tempat terjadinya inflamasi didominasi sebaran warna putih, sedangkan kaki kanan memiliki sebaran warna merah, kuning, dan hijau. Sebaran warna 
pada skala temperatur sudah diatur sedemikian rupa hingga terbagi menjadi 4 bagian. Skala temperatur yang digunakan dengan range $10^{\circ} \mathrm{C}$, mulai dari $26^{\circ} \mathrm{C}$ hingga $36^{\circ} \mathrm{C}$. Data yang ditunjukan pada Tabel 1 dijadikan sebagai pedoman dalam mengklasifikasikan bagian warna sesuai temperaturnya

\section{Citra Grayscale}

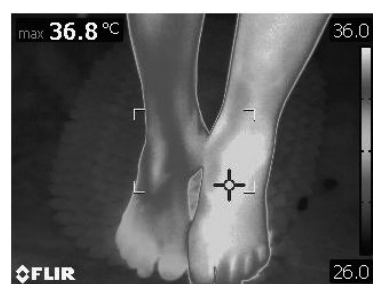

(a)

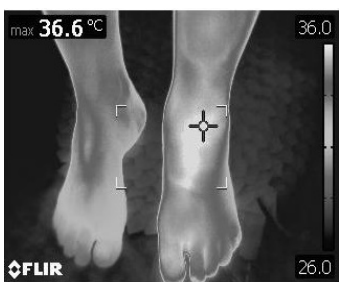

(b)
Gambar 4.

Hasil Citra Graycale

(a) sebelum pemulihan; (b) setelah pemulihan.

Citra grayscale pada Gambar 4 merupakan hasil dari konversi citra rgb menjadi bentuk tampilan grayscale. Citra ini termasuk dalam tahapan dari pre-processing pengolahan citra. Citra grayscale berguna untuk menyederhanakan informasi yang terdapat pada citra RGB. Informasi yang dimaksud adalah ketika citra RGB memiliki 3 komponen warna, citra grayscale hanya memiliki 1 komponen. Fungsi dari grayscale ini adalah menyatukan 3 komponen warna citra RGB (red,green,blue) menjadi 1 komponen warna pada aras keabuan (grayscale). Nilai intensitas pada graycale ini bergantung pada kedalaman citra yang dimiliki. Citra grayscale yang dihasilkan pada penelitian ini mempunyai ukuran kedalaman 8 bit untuk setiap pixelnya. Setiap pixelnya memiliki varian nilai intensitas, $\mathrm{n}$ merupakan kedalam bitnya. Berdasarkan hasil perhitungan tersebut, maka citra grayscale ini memiliki variasi nilai intensitas sejumlah 256 variasi dari angka 0-255. Citra thermal yang semula (Gambar 3.) memiliki bermacam variasi warna dan setelah diubah kedalam bentuk grayscale (Gambar 4.) menjadi lebih sederhana. Variasi intensitas warna dari yang paling gelap (0) hingga paling terang diangka (255). Proses ini diperlukan sebelum masuk ke tahap thresholding dikarenakan operasi threshold hanya bisa dilakukan pada citra dengan satu komponen warna saja. Secara lebih jelas informasi antara kedua kondisi pada citra grayscale dapat diamati dalam sebuah histogram.

\section{Histogram Citra Grayscale}

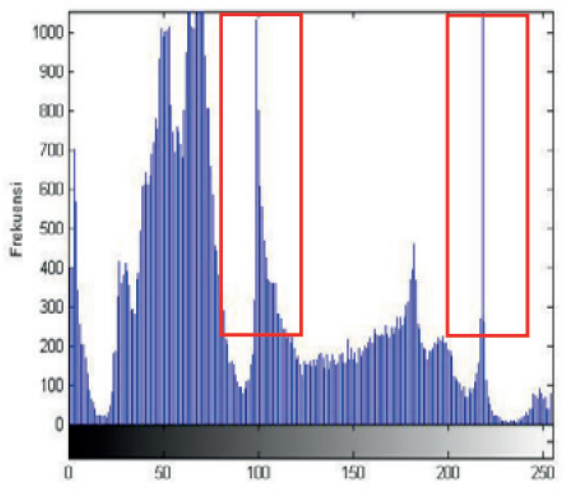

(a)

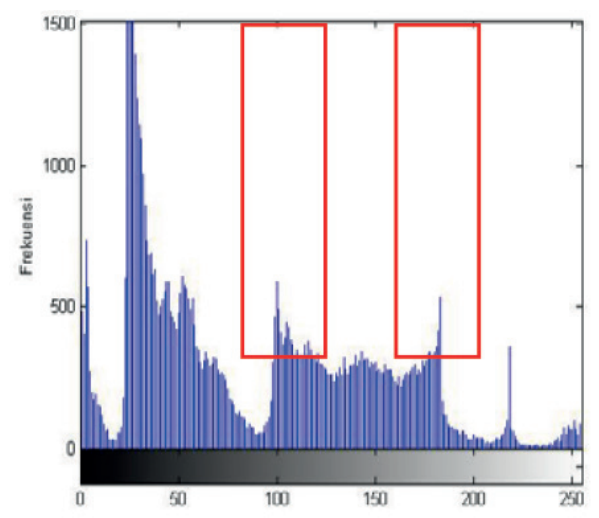

(b)

Gambar 5.

Histogram Citra Grayscale Menunjukan Frekuensi Tiap Nilai Intensitas Warna Aras Keabuan (a) sebelum pemulihan; (b) setelah pemulihan

Melalui citra grayscale yang ditunjukan melalui Gambar 4 dapat ditampilkan suatu histogram yang ditunjukan pada Gambar 5. Dari kedua histogram tersebut dapat disimpulkan bahwa nilai grayscale level diatas 100 sudah berkurang frekuensinya pada kondisi setelah pemulihan. Hal tersebut menandakan bahwa area dengan temperatur yang relatif tinggi pada citra berkurang pada kondisi setelah pemulihan. 


\section{Adjust Contrast}

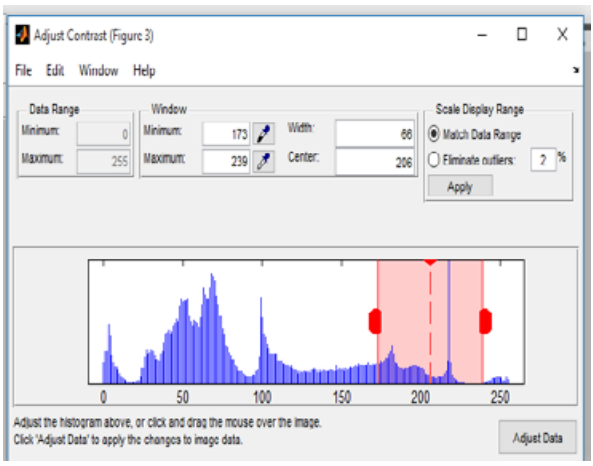

(a)

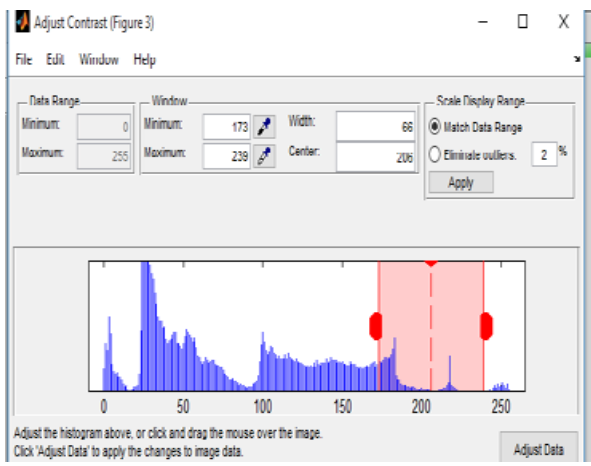

(b)

Gambar 6.

Tampilan Adjust Contrast Dari Kedua Citra Grayscale

Lebar nilai intensitas (window level) yang ditujukan Gambar 6 pada kedua kondisi (a) dan (b) diatur dengan nilai yang sama di angka min:173 dan max:239 agar citra area inflamasi nampak lebih jelas.

\section{Hasil citra setelah contrast adjustment}

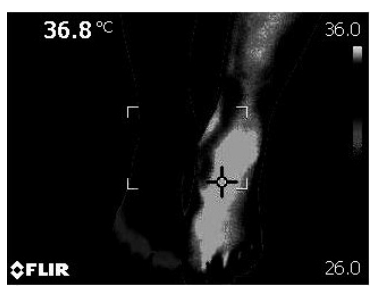

(a)

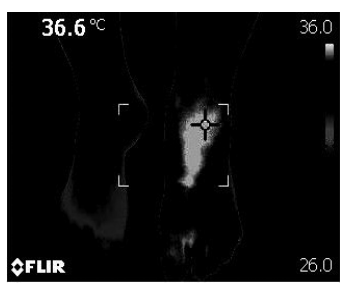

(b)
Gambar 7.

Citra Grayscale Hasil Adjust Contrast
Tahapan adjust contrast digunakan untuk mengatur kontras yang terdapat pada citra grayscale. Caranya dengan menemukan kombinasi angka yang tepat dan sama pada citra agar menampilkan area inflamasi dengan lebih jelas pada kedua citranya yang ditunukan pada Gambar 7 (a) dan (b). Setelah menemukan kombinasi nilai kontras yang tepat, nampak bahwa pada bagian kaki dengan nilai intensitas mencolok (tinggi) akan terlihat dibanding area lain disekitarnya. Tahap adjust kontras ini tidak mempengaruhi operasi threshold yang akan dilakukan pada proses berikutnya. Tahap ini hanya bertujuan melihat sejauh mana citra grayscale dapat membedakan area yang memiliki intensitas paling tinggi pada kaki dengan cara mengatur level kontrasnya. Level kontras yang dimaksud adalah window level. Window level merupakan lebar jarak pada nilai kontras grayscale dari titik 0-255. Terbukti pada Gambar 5. (a) dan (b) bahwa dengan mengatur pada window level di angka tertentu dapat memperlihatkan bagian objek yang memiliki intensitas warna paling tinggi.

\section{Thresholding}

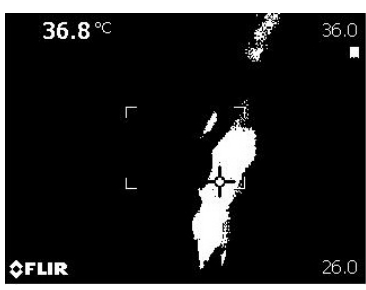

(a)

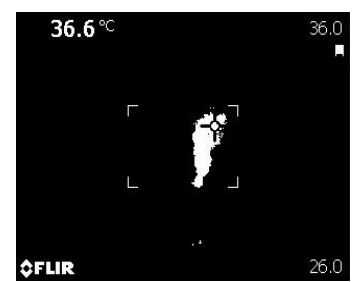

(b)
Gambar 8.

Citra Hasil Operasi Thresholding Dengan Nilai Threshold $\mathrm{T}=0.8$.

Warna putih (foreground) menunjukan area inflamasi kedua kondisi pada Gamabr 8 (a) sebelum dan (b) sesudah pemulihan. Operasi thresholding diterapkan guna menkonversi citra grayscale menjadi citra hitam dan putih (biner). Dalam proses ini dibutuhkan suatu nilai batas yang disebut dengan nilai threshold. Nilai intensitas citra $\geq$ nilai threshold diubah menjadi 1 (berwarna putih), sedangkan nilai intensitas citra < nilai threshold diubah menjadi 0 (berwana hitam). Dalam penelitian 
ini telah ditentukan nilai threshold yang tepat untuk kedua kasus (a) dan (b). Nilai threshold ini berfungsi sebagai batasan untuk menerjemahkan 256 intensitas (dari 0-255) menjadi 2 intensitas saja (0 dan 1 ). Hasil operasi dengan nilai threshold 0.8 tersebut mampu memisahkan objek (foreground) yang ingin diamati (area inflamasi) dengan background disekitarnya. Background yang dimaksud mulai dari area yang bukan merupakan bagian kaki, hingga bagian kaki yang memiliki temperatur seragam (uniform).

\section{Menghitung luasan area inflamasi}

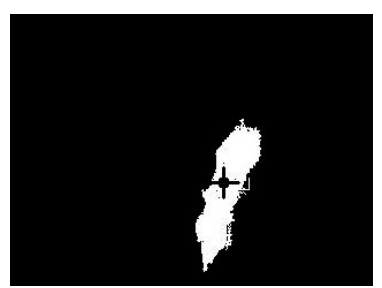

(a)

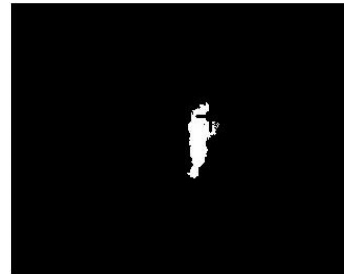

(b)

Gambar 9.

Citra Biner Hasil Seleksi Bwareaopen Melalui Hasil Citra Operasi Thresholding (Gambar 6)

Fungsi bwareaopen berhasil menghilangkan area foreground (putih) yang memiliki jumlah sangat kecil pada area sekitar terjadinya inflamasi. Terdapat perbedaan luasan area foreground (putih) yang cukup signifikan antara kedua kondisi. Kondisi setelah pemulihan (b) memiliki luasan area yang lebih kecil dibandingkan kondisi sebelum pemulihan (a). Hasil luasan area inflamasi oleh citra pada kondisi sebelum pemulihan adalah $\mathrm{L}(\mathrm{a})=$ 3176.5 pixel sedangkan luas area pada kondisi setelah pemulihan adalah $\mathrm{L}(\mathrm{b})=938$ pixel. Nilai luas area tersebut dihitung berdasarkan jumlah pixel yang terdapat pada area foreground (putih). Tahap bwareaopen berfungsi untuk menghilangkan komponen warna putih yang memiliki jumlah kurang dari nilai $P$ suatu pixel citra biner. Nilai yang tepat pada peneltian ini ditentukan dengan nilai $P=500$. Nilai tersebut berhasil menghilangkan bagian kecil diluar area inflamasi yang tidak diinginkan.
Setelah diketahui luas area inflamasi berdasarkan jumlah nilai pixel, perlu adanya konversi untuk menjadikan luas area tersebut kedalam bentuk nyata dengan satuan $\mathrm{cm}^{2}$. Untuk menkonversi menjadi bentuk $\mathrm{cm}^{2}$, maka diperlukan sebuah faktor konversi. Faktor konversi yang diperlukan adalah resolusi spasial pada citra yang dihasilkan oleh KIT. Resolusi spasial merupakan ketelitian sebuah citra untuk menampilkan objek dengan jelas. Sebelum mengetahui suatu resolusi spasial pada citra diperlukan informasi mengenai panjang yang dimiliki sebuah pixel. Seperti yang telah disebutkan pada metode penelitian bahwa pada jarak sekitar 1 meter dari objek, KIT menghasilkan citra dengan panjang 1.36 mm untuk setiap pixel yang dimilikinya. Berdasarkan data yang telah diperoleh maka dapat dihitung luasan area inflamasi dari kedua citra. Luas area pada kondisi sebelum pemulihan (a) menggunakan persamaan 4 didapatkan sebesar $58.75 \mathrm{~cm}^{2}$, sedangkan untuk luas area pada kondisi setelah pemulihan (b) ialah 17.35 $\mathrm{cm}^{2}$. Berdasarkan hasil tersebut, maka citra pada kondisi setelah pemulihan Gambar 9(b) memiliki luas area yang jauh lebih kecil daripada kondisi sebelum pemulihan Gambar 10(b). Luas area yang ditampilkan dalam satuan $\left(\mathrm{cm}^{2}\right)$ ini memrepresentasikan luas area inflamasi pada kaki yang terdeteksi oleh KIT.

\section{SIMPULAN}

Pengolahan citra thermal menggunakan metode global thresholding mampu memisahkan area inflamasi dengan area normal pada bagian tubuh. Selain itu juga dapat mengetahui kisaran luasan sesungguhnya area kaki yang mengalami inflamasi. Perbandingkan kedua citra pada kedua kondisi yang berbeda (awal dan pasca pemulihan) menunjukan bahwa terdapat kemajuan dalam proses penyembuhan pada area inflamasi dari data hasil perhitungan luasan area yang ditampilkan pada citra biner secara komputasi. Berdasarkan data yang disajikan dapat diamatu bahwa penerapan pengolahan citra pada hasil citra KIT dapat membantu memetakan masalah inflamasi yang terletak di suatu bagian tubuh manusia. 
DAFTAR PUSTAKA

Anonym. (2016). User's manual: FLIR Exx series. Retrieved from FLIR Manuals website: http://www.omega.com/ manuals/manualpdf/M5162.pdf

Anonym. (2018). What is infrared. Retrieved August 10, 2018, from https://www. flir.com/discover/what-is-infrared/

Brody, W. (2000). Handbook of Medical Imaging Processing and Analysis (I. Bankman, Ed.). London: Academic Press.

Bushberg, J. T. (2012). The Essential Physics of Medical Imaging (Third).Philadelphia, PA: Lippincott Williams and Wilkins.

Cardone, D., \& Merla, A. (2017). New frontiers for applications of thermal infrared imaging devices: Computational psychopshysiology in the neurosciences. Sensors (Switzerland), 17(5). https://doi.org/10.3390/ s17051042

Fluke. (2010). Thermography Terms Explained: FOV, IFOV, IFOV measurement. Retrieved July 18, 2018, from http://thermal-imagingblog.com/index.php/2010/03/10/ thermography-terms-explainedfov-ifov-ifovmeasurement-on-yourinfrared-camera/\#.W0ylHjF9jIX
Gurjarpadhye, A. A., Parekh, M. B., Dubnika, A., Rajadas, J., \& Inayathullah, M. (2015). Infrared Imaging Tools for Diagnostic Applications in Dermatology.SMJournalofClinicaland Medical Imaging, 1(1), 1-5. Retrieved from http://www.ncbi.nlm.nih. gov/pubmed/26691203\%0Ahttp:/ / $\mathrm{w} w \mathrm{w} \cdot \mathrm{pu} \mathrm{b} \mathrm{m}$ e d c e n t r a 1 . nih.gov/articlerender. fcgi?artid=PMC4683617

Lasanen, R. (2015). Infrared thermography in the evaluation of skin temperature: Applications in musculoskeletal conditions. Retrieved from http:// epublications.uef.fi/pub/urn_ isbn_978-952-61-1880-2/urn_ isbn_978-952-61-1880-2.pdf

Maslebu, G., Adi, K., \& Suryono. (2016). Using computer aided system to determine the maximum depth of visualization of B-Mode diagnostic ultrasound image. Journal of Physics: Conference Series, 694(1). https:// doi.org/10.1088/17426596/694/1/012052

Nahm, F. (2013). Infrared Thermography in Medicine. 59(3), 123-130.

Ranosz-Janicka, I., Lis-Święty, A., SkrzypekSalamon, A., \& Brzezińska-Wcisło, L. ammation in localized scleroderma with thermal imaging. Skin Research and Technology, 25(2), 118-123. https://doi.org/10.1111/srt.12619 